\title{
The Teacher
}

\section{The Professor's Dream: Getting Students to Talk and Read Intelligently}

\author{
Andrew Green and William Rose, Connecticut College
}

$\boldsymbol{S}$ pellbinding lecturers we are not. Rarely do students greet our words with mouths agape and heads straining forward in a vain attempt to hear the next phrase, the next pearl of wisdom.

Perhaps this is just as well, for learning is an active process and not a passive spectator sport. However, use of the most common pedagogic alternative, the Socratic method, is fraught with peril-especially at the undergraduate level. Even if students are able to get past the inherent tension of the classroom and their personal insecurities about speaking up, how much can we faculty expect them to get out of a reading unless it is rudimentary? Can we give students a chapter from Max Weber, Kenneth Waltz, Peter Evans, or any other serious theorist and expect them to comprehend and retain the material and speak intelligently in class as the Socratic method demands? Many students want to prepare and participate more effectively, but do not know how. Texts are often too easy and straightforward, and do not teach students how to analyze complex, sophisticated material on their own. Yet more sophisticated readings, unassisted, leave them at sea.

For the past several years, we have experimented with a modified Socratic approach that is designed to allow us to teach undergraduate courses using advanced concepts and readings, simultaneously affording students fair opportunity to carry the bulk of discussion in class in a way that succeeds. The system outlined below is a flexible mechanism for fostering greater student participation at a higher level of sophistication and complexity. We have used it successfully across a wide spectrum of applications, from a modest com- plement to the more conventional lecture format to a complete substitute for lectures. We believe it can readily be used in a range of political science courses and probably in other disciplines as well.

It also enables an old dog to learn new tricks. Although the first author pioneered the method and has always used it, the second author adopted it twelve years into his teaching career. Each has seen impressive results. What is more, we each have different styles of teaching, and we have found the method readily adaptable.

This modified Socratic approach has two components: first, question sheets designed to prepare students to participate in class, and second, classroom management techniques which encourage students to do so.

\section{How Study Questions Work}

At the end of each class, students are given a list of about a dozen questions as a guide in their reading and preparation of the next assignment. Under each question, space is left for them to write notes for their answers. These questions are not designed to serve as a mini-quiz, to be recited in a rote manner at the following class. Rather they are a mechanism to guide students through the reading, to tell them what is important in the assignment, and to suggest what they need to think about and talk about in the classroom meeting.

1. Questions help students separate the wheat from the chaff. Twenty pages of Weber often contain more ideas than can be discussed at the introductory level in weeks, much less an hour-long class period. The questions serve to focus their attention on the elements of the reading that are most important. This alleviates student concern and confusion about what they are supposed to take from a reading. With the questions, both you and they know what will be discussed in the next session.

You can signal the relative importance of different questions by altering the size of the space left below them for their notes. Some questions are very simple and straightforward (we usually try to begin with a couple of relatively easy ones). These questions introduce a key concept or condition but do not require an elaborate explanation. Others are more important or require more elaboration, which can be communicated by the space left for answers.

2. Question lists allow the instructor to bring to bear the students' knowledge from prior assignments and issues previously discussed. Normally, if the professor asks a student to compare two authors on the spot the student is unlikely to give a thoughtful answer. Questions enable you to give students warning that you want them to be prepared to compare two ideas or two authors. We find that asking students to read an assignment with someone else's ideas in mind is not worthwhile if we fail to give them those ideas in written form: without hard-copy, students are much more likely to simply forget. The written question is a strong, simple form of reinforcement.

3. Knowing the questions in advance allows students to prepare. Many students are intimidated by the idea of having to talk and voice an opinion in class. Since questions allow them to prepare in advance and have notes available, there is 
less anxiety associated with the idea of being called upon to talk in class.

Understanding complicated ideas involves some prior preparations.

For example, a question can direct students to rephrase a quotation in their own words. Or it could ask students to interpret for themselves and the class a key passage that at first glance appears quite complex and difficult to decifer, but which, when examined phrase by phrase, is within their abilities.

Students can also be asked to assess a scholar's ideas. A question could require them, for example, to understand a proposition and to evaluate arguments by examining the evidence before coming to class. Questions may also prepare students to defend their own assessments against the arguments of others.

4. Question lists may also serve as a class guide for the instructor. One of the dangers of teaching Socratically is that it is easy for the discussion to veer away from the central issue that you wish to cover. Question lists provide a road map to which the instructor can always return. Without the questions, we find it difficult to keep track of whether the important points were covered within a class session.

Although most study questions enable students to come to class with appropriate understandings or assessments, some issues are too complex for students to comprehend on their own. An appropriate question can at least start a student's thinking processes and remind the instructor to go over the issue in class-allowing students to grapple with complicated ideas.

\section{Preparing Study Questions}

Study sheets are very valuable but require considerable preparation. It takes time to read materials students are assigned and to figure out how to integrate them into a classroom agenda. It also takes time to write study questions that will accomplish your objectives. For this reason, we recommend that instructors using the method for the first time introduce it to just one course. Once you have succeeded in using the method in one course, it is safer to introduce it to more than one course at a time-remembering that doing so will take a great deal of time.

Since students have different learning styles and approach study questions in different ways. Most students complete the questions by giving attention to each question sequentially. Others resent writing answers to minor questions and prefer to concentrate on larger issues. If the major questions appear at the end of the question list, these students may never get to them. We have found several ways to curb this tendency. One option is to summarize major questions and concepts in an introductory paragraph so that students know what is expected of them and where the study questions will lead. Another option is to invite students to read the study sheet before they begin the readings, so that they have a larger picture of what to look for in a reading. This is always a good idea, but it is especially helpful for students who prefer not to write down answers to the study questions.

At the beginning of a semester, when introducing the idea of study questions, it helps to say that you are aware of different learning styles and approaches to study questions. Students then feel that they are being treated like adults, with options to prepare for class that they can tailor to their own needs. Of course there is more the instructor needs to say about this teaching method, and we will cover it below under "Classroom Management"-after discussing a final aspect of preparation.

The second time this method is used in a given course, some revisions to study sheets may be necessary. To facilitate this, we recommend that instructors reflect on the session and on the study questions, and jot down suggested improvements. Typically, we find that the second round of study sheets has fewer questions that are more likely to highlight important ideas.

\section{Classroom Management}

Of course, question sheets alone will not get passive students to be active in class. We are convinced that most students want to partici- pate, but are either too shy or too fearful. Every class has a few dominant contributors. The challenge of this method is in getting the others, the quiet, passive students, involved. How do you get them to talk?

An emphasis on class participation in determining final grades is the traditional weapon and we generally count it from 15-30 percent of the student's course grade. Yet we believe that the success of this method is much more dependent on the creation of a classroom atmosphere within which students feel comfortable taking risks-answering questions when they are not entirely confident they are right - in front of you and in front of their peers.

We believe it is crucial from the outset to establish the classroom as a place where mistakes are expected, where one wrong answer does not consign a student to the darkest regions of humiliation, where learning is a process of trial and error. We tell students that very few people feel comfortable talking in front of others-especially when they are not sure of their grasp of the materialbut that it is a critical skill to acquire. Talking in class gives students the opportunity to learn how to think better and articulate their thoughts more effectively. Dealing with the pressure involved in speaking up is better learned in class than in a more consequential context like an important interview or meeting with a supervisor. If a student is struggling with a question, you can simply ask someone else to help, and move on. As the class session proceeds, the first student typically has another chance to redeem him or herself.

We continually stress to our students that the material is difficult and that we do not expect them to come in with all the answers; if they could, the material would be too simple. We also stress that what matters most is not that they understand a day's reading when they enter class, but that they understand it when they leave. We emphasize that the class is as much about the process of figuring out how a theory or concept works as it is about learning the substantive material itself.

It is very easy to find class time repeatedly dominated by the same 
few hands but the class only works if you can coax, encourage, and elicit the participation of all or almost all students. This does not require every student to speak during every session. Yet if a critical mass of participants is achieved, then the class can take off and your role becomes more of a moderator and facilitator rather than the sole supplier of information. This will not happen of its own accord; you must actively encourage shy and insecure students. Tell them that you have faith in them; assure them that they will do fine. Make sure to start off the session with relatively easy questions that build confidence, and when quieter students raise their hands, give them priority. Many students who hang back want to participate, but need help engaging in this sometimes terrifying venture.

Some of our most satisfying experiences as teachers have been when students who are usually quite capable tell us how glad they are to have overcome the fear of talking in front of others and how satisfied they feel. Semesters usually begin with many nervous students wondering what they have gotten themselves into. But by the end of the semester, most are more confident (even combative) and feel that they have really accomplished something of value. But they do require near-constant nurturing.

A professor's style of teaching will affect classroom management. The first author often calls on students randomly which is an extra incentive both to be prepared and to volunteer. The second author calls only on volunteers; this removes some tension from the classroom but then a few shy students tend to remain quiet. Getting a critical mass of students to volunteer sometimes requires an extra effort, such as meeting with quiet students to encourage their participation. The second author also offers students in the introductory IR course an alternative-an extra short paper or a final exam question that can substitute for the class participation grade. For this to work, students need to learn their participation grades near the end of the semester in order to choose between an oral or written form of evaluation. Typically only about five percent of the students take this alternative route; almost all of the others are active participants.

Teaching with the modified Socratic method also requires a much different form of preparation than the more conventional lecture approach. Despite having the question sheet as a guide, it is impossible to predict exactly where student responses will take class discussion on a given day. Faculty need to manage their classes on their feet, and keep classes from drifting too far afield. You need to be prepared for a wider range of questions and have a more intimate grasp of the material because you have less control over the direction of the class hour. The questions give the class meeting a skeletal structure but student answers and subsequent questions may take you a considerable distance from your anticipated line of inquiry in a way that does not occur with planned lectures. While you always have the ability to pull in the reins and get the class back on the anticipated track, it is also important, on occasion, to allow the students to run with their ideas and follow them to their logical conclusion. You have to be prepared and willing for the class to do so. If you emphasize the importance of independent thinking on their part, sometimes you will be rewarded with a surplus.

\section{Limitations and Benefits}

There are other trade-offs that this method requires but overall we believe that the benefits outweigh the drawbacks.

Because much, if not all, of the class is taken up by discussion, it is not possible to get through as much material as you can in a lecture. We typically assign only as much reading as we can discuss in a class session. This is a particular problem in survey courses where there is a lot of pressure to cover a long list of topics. On the other hand, when students know that they will be required to discuss a reading and will actually have the opportunity to do so, they are much more likely to do the reading. In our experience, students fail to read, not because they are lazy or indolent, or because there is too much reading; rather they do not read because they see no compelling reason to do so. Oftentimes faculty assign texts that they subsequently regurgitate in lecture, ignore altogether, or do not refer to in exams and/or papers.

This method requires faculty to give up much of the bully pulpit. The more students talk, the less faculty do. It also requires a commitment not to rush in and answer, but to allow students to do so- even if their answers may be less elegant and complete. This is not always easy. Of course there will be times you will want to fill in gaps of information or summarize a strand of comments more coherently.

Finally, the larger the class size, the greater the problem in establishing the kind of intimate, trusting relationship with students that makes them willing to go out on that limb. Large classes also enhance student frustration at not being able to speak on a regular basis. We have found forty to be the upper limit on this type of class but that is about the upper limit for most courses at small, liberal arts colleges like Connecticut College.

Despite these limitations, we have found that the student response to this teaching format has been unequivocal, as have been the benefits to us. We would like to conclude by discussing some of the many benefits derived from greater, more active, and more sophisticated student participation.

Students are active, attentive, and energetic in class. Listening to lectures day after day teaches students to take a passive attitude toward class. Many do not bother with the reading because they know it will be covered in lecture. In our classes, by contrast, students know they are going to called upon to participate, and most, though certainly not all, are alert. It also increases likelihood that they will do the reading as the opportunity cost of being unprepared in front of their peers can be quite high. This vastly improves the quality of class participation. Participation, in turn, enhances their verbal skills, their ability to think under pressure, and, by the end of the semester, increases their confidence. This method helps teach students how to 
think and speak on their feet, a valuable skill that comes naturally to few, but is of benefit to everyone.

Since you can assess their comprehension of the reading assignments on an ongoing basis, you can freely assign written assignments of greater interest to you and the studentsbecause a full series of written tests on the material is less important. In courses beyond the introductory level, for example, neither of us have final exams. Instead, students do more independent research, like an extra short paper or a more in-depth term paper. The ongoing feedback from class participation also lets professors know more quickly and effectively than weekly quizzes if students are comprehending the material. Because you help them through the material, you can assign more sophisticated readings.
Finally, we have found that this method leads to much more satisfying interaction with students. It challenges both the students and us. Class is less predictable, less scripted, more spontaneous; and students have, by virtue of their responses, often caused us to view an issue taught many times before in a new light. They have taught us in turn. The method also requires the instructor to learn all student names; this personalizes classroom interactions and helps to create a greater sense of community and common cause.

In sum, whether it is adopted in part or in whole, we are convinced that a modified Socratic approach can do much more to improve undergraduate teaching-unless you happen to be one of those rare, spellbinding lecturers.

\section{About the Authors}

\begin{abstract}
Andrew Green is assistant professor of Government at Connecticut College. $\mathrm{He}$ has published on the automobile and semiconductor sectors, and is writing a book about the development of South Korea's high technology industries.
\end{abstract}
William Rose is asso- ciate professor of Government at Con- necticut College. His teaching and research focus is on interna- tional security and foreign policy. He is co-author of The Role of the United States in a Changing World: Choices for the 21st Century (Dushkin Press Group, 1993).
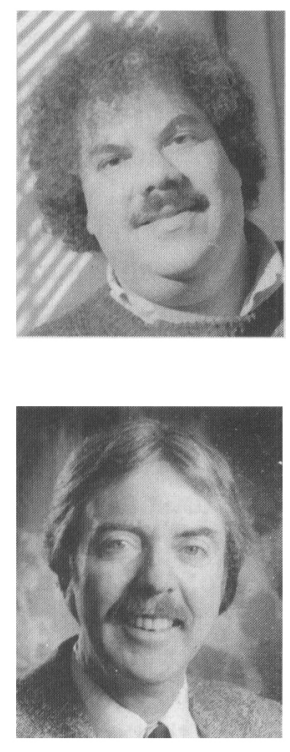

\section{Designing In-Class Simulations ${ }^{1}$}

\section{Elizabeth T. Smith and Mark A. Boyer, University of Connecticut}

\begin{abstract}
Editors Note: The following article currently appears as the first teaching article on the APSA World Wide Web site. In addition to the text, the version appearing on the web site will contain two appendixes which include a sample economic policy-making simulation and a supplemental reading list on active learning pedagogy and evaluation of student learning. This site can be accessed at http://www2.dgsys. com/ apsa/ps.html. In the future additional articles from the pages of PS will appear, including articles of special interest from the Features, Teaching and Profession sections.
\end{abstract}

S imulations have long been part of scientific research methods. Meteorologists use computer simulations to help predict the path of weather fronts; economists use them to make economic forecasts for an economy; military strategists use simulations to conjecture about the course of events during military campaigns; the list goes on. Less traditional, however, is the use of simulation as a teaching tool.

Sometimes viewed by one's colleagues as merely "playing games" in the classroom, simulation has been perceived in some teaching environments as diverting faculty and student attention away from the main goal: absorbing the lessons. But even when teachers are sympathetic to an active learning approach, the use of simulation in the classroom is often hindered by a lack of available and applicable simulations on relevant topics. Simulation use is also impeded by a lack of good guidelines for developing effective simulations.

\section{Simulations and Active Learning}

Simulations have the power to recreate complex, dynamic political processes in the classroom, allowing students to examine the motivations, behavioral constraints, resources and interactions among institutional actors. Woodworth and Gump argue that simulations "provide the laboratories for political science" (Woodworth and Gump 1994); indeed they do provide such laboratories, even if imperfect ones. After a simulation, participants have a deeper understanding of institutions, their successes and failures.

Using simulations in the classroom is one way of encouraging student participation. Other types of active learning approaches include case teaching, discussion teaching more generally, or even the use of hands-on exercises. The active learning approaches:

(1) seek to give students a deeper level of insight into the political process

(2) encourage students to be more attentive and more active in the learning process

(3) help students retain information for longer periods of time 